\title{
Ervaringen met Stereo-EEG RadioFrequente ThermoCoagulatie
}

In deze bijdrage een weergave van de ervaringen met thermocoagulatie van epileptogene zones in het Academisch Centrum voor Epileptologie, Kempenhaeghe/MUMC+. Besproken worden de uitkomst na behandeling (wel/niet aanvalsvrij) in relatie met verschillen in lokalisatie, type onderliggend lijden en uitgebreidheid van de epileptogene zone, evenals mogelijke complicaties na behandeling. De afgelopen jaren is het indicatiegebied iets uitgebreid maar het grootste deel bestaat uit patiënten met periventriculaire heterotopieën.

Om bij patiënten met refractaire epilepsie vast te stellen of een resectieve operatie mogelijk is, wordt op indicatie een Stereo-EEG (SEEG) onderzoek uitgevoerd. Indien tijdens dit onderzoek blijkt dat een of meer van de elektroden in de seizure onset zone (SOZ) geplaatst zijn dan is het ook mogelijk om, tijdens dezelfde opname, via deze al aanwezige elektroden middels radiofrequente thermocoagulatie (RFTC) ter plekke stukjes brein uit te schakelen door lokale verhitting. Aangezien voorafgaand aan de RFTC met behulp van elektrostimulatie over de aanwezige elektroden ook heel lokaal functioneel onderzoek gedaan wordt kan de kans op complicaties nadien geminimaliseerd worden. Middels bipolaire coagulatie worden laesies met een diameter van circa drie tot vier $\mathrm{mm}$ gecreëerd. In figuur $\mathrm{I}$ is een glas met rauw eiwit te zien, een substantie met een consistentie die die van het brein enigszins benadert, met daarin het type SEEG-elektrode (DIXI, Beçancon) en het resultaat van RFTC: Het witte bolletje onderaan de elektrode is het coagulaat.

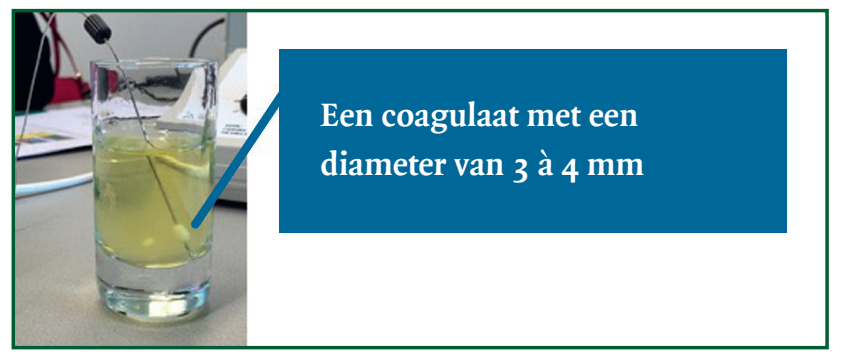

Figuur 1 Een voorbeeld van RFTC in eiwit.

Als RFTC leidt tot aanvalsvrijheid, wordt een open hersenoperatie voorkomen. Het resultaat van deze behandeling heeft echter ook een diagnostische waarde. Als er een forse aanvalsvermindering is na toepassing van RFTC, ook al is die tijdelijk, heeft dit een hoge positief voorspellende waarde voor een succesvolle navolgende resectie. De kans op aanvalsvrijheid na RFTC is geassocieerd met de aard van het onderliggend lijden.

\section{Het wat en waar}

In het Academisch Centrum voor Epileptologie (ACE), Kempenhaeghe/MUMC+ werd na overleg over de technische aspecten, met zowel verscheidene Franse centra als ook het Milanese centrum waar reeds RFTC werd toegepast, in 2016 begonnen met RFTC. De implantatie en de explantatie van de diepte-elektroden vindt plaats in het Maastricht Universitair Medisch Centrum (MUMC+), terwijl registratie en eventuele coagulatie plaatsvindt in Kempenhaeghe. Coagulatie wordt in de ochtend gedaan, zodat explantatie van de elektroden nog op dezelfde dag gedaan kan worden. Aanvankelijk werden uitsluitend patiënten met periventriculaire heterotopie (PVH) met RFTC behandeld, sinds 2018 gebeurt dit ook bij andere indicaties.

Tussen 2016 en februari 2020 werd bij 26 patiënten RFTC toegepast, waarvan zestien patiënten met PVH, zeven met andere laesies en drie zonder een zichtbare epileptogene laesie op een 3 Tesla MRI. In tabel $\mathrm{I}$ is een overzicht gegeven van de aard van de afwijking die de oorzaak was van de epilepsie en het resultaat van de behandeling bij de laatste controle.

\section{Periventriculaire heterotopie}

De patiënten met een PVH hadden diep-gelegen laesies, 


\begin{tabular}{|c|c|c|c|c|c|c|}
\hline \multirow[b]{2}{*}{ Aard afwijking } & \multicolumn{3}{|c|}{ Effect RFTC } & \multicolumn{2}{|c|}{ Resectie na SEEG } & \multirow[t]{2}{*}{ Totaal } \\
\hline & Aanvalsvrij & Verbetering & Geen verbetering & Ja & Nee & \\
\hline PVH & 8 & 6 & 2 & 0 & I6 & I6 \\
\hline FCD & I & 0 & 0 & I & 0 & I \\
\hline HS & I & 2 & o & 2 & I & 3 \\
\hline Encefalomalacie & o & I & o & 0 & I & I \\
\hline Cavernoom & o & I & o & 0 & $I^{\star}$ & I \\
\hline Gliose & o & I & o & 0 & I & I \\
\hline Geen & 2 & I & o & 0 & 3 & 3 \\
\hline Totaal & I2 & $\mathrm{I} 2$ & 2 & 3 & 23 & 26 \\
\hline
\end{tabular}

Tabel 1 Aard afwijking MRI versus effect RFTC en beleid na SEEG-onderzoek [ N.B. PVH: periventriculaire heterotopie, FCD: focale corticale dysplasie, HS: hippocampus sclerose]. ${ }^{*}$ wacht op resectie.

deels in de dominante hemisfeer, waarbij resectie niet de eerste keuze was. Er werden aanvankelijk negentien patienten met een PVH aangemeld en geïmplanteerd. Bij drie hiervan heeft geen RFTC plaatsgevonden vanwege I) een bloedingscomplicatie ten gevolgen van de diepte-elektroden implantatie waardoor geen registratie meer mogelijk was (maar sindsdien bestaat er wel al meer dan vier jaar aanvalsvrijheid), 2) voortijdig afgebroken registratie op verzoek van patiënt ten gevolge van te lage psychische draagkracht, en 3) een epileptogene zone elders dan de PVH. Gezien de huidige kennis lijkt het succes van RFTC het grootst te zijn bij de patiënten met een PVH. In onze groep zijn acht van de zestien patiënten met een PVH aanvalsvrij geworden met een follow-up tijd van I2 tot 57 maanden, met een gemiddelde van 27 maanden. De aantallen van patiënten met andere aandoeningen zijn vooralsnog te klein om conclusies te kunnen trekken.
Bij de zestien patiënten met een PVH zijn er in totaal tweeëntwintig SEEG-onderzoeken mét coagulatie gedaan, bij elf patiënten eenmalig, bij vier patiënten tweemaal en bij één patiënt driemaal. Reden voor de herhalingen waren het niet geheel aanvalsvrij worden na de voorgaande procedure terwijl er op post-coagulatie MRI nog resterend heterotopisch weefsel aanwezig was. De locatie van de PVH makkt dat deze patiënten niet in aanmerking komen voor resectieve chirurgie.

Voor acht SEEG-onderzoeken werd RFTC in een enkele sessie uitgevoerd (zoals internationaal gebruikelijk), bij zestien van die onderzoeken in twee sessies en bij twee onderzoeken verdeeld over drie sessies. De reden voor meer dan één coagulatiesessie was dat er één tot drie uur na de coagulatie nog epileptiforme ontladingen voorkwamen in het SEEG, zelfs op contactpunten die ook volgens

\begin{tabular}{|c|c|c|c|c|c|}
\hline & & \multicolumn{4}{|c|}{ Effect_RFTC } \\
\hline & & Aanvalsvrij & Verbetering & Geen verbetering & Totaal \\
\hline \multirow[t]{6}{*}{ PVH_aantal noduli } & I & I & 2 & 2 & 5 \\
\hline & 2 & I & I & 0 & 2 \\
\hline & $3-5$ & I & I & 0 & 2 \\
\hline & 6-10 & 2 & I & 0 & 3 \\
\hline & $>10$ & I & I & 0 & 2 \\
\hline & $\begin{array}{l}\text { geen noduli maar } \\
\text { soort band of } \\
\text { kralensnoer }\end{array}$ & I & I & 0 & 2 \\
\hline Totaal & & 7 & 7 & 2 & I6 \\
\hline
\end{tabular}


de MRI in heterotopisch weefsel lagen. Het aantal laesies dat per SEEG-onderzoek gemaakt is, varieerde van $\mathrm{I}$ tot $6_{5}$, met een gemiddelde van I9,45. Bij de SEEG-onderzoeken mét RFTC voor andere indicaties dan PVH was dit 4 tot 22, met een gemiddelde van Io,45 laesies.

Samenvattend blijkt in de populatie RFTC bij $43,25 \%$ van het totaal aantal patiënten te leiden tot aanvalsvrijheid en een overeenkomstig percentage tot een verbetering van "slechts" meer dan 50\% aanvalsreductie. Bij de PVH-groep lijkt er geen relatie te bestaan tussen het effect op de aanvalsfrequentie en het aantal PVH noduli (tabel 2). Zowel uni-of bilaterale aanwezigheid (lateralisatie) van PVH als ook de lokalisatie van de noduli tonen geen evidente relatie met het resultaat van de RFTC-behandeling (tabel 3).

Het is gebruikelijk dat tijdens een SEEG-onderzoek neurologische functies ter plaatse van de diepte-elektroden worden gelokaliseerd. Een enkele keer is na uitgebreid overleg met de patiënt en de rest van het team, ondanks aangetoonde functie bij elektrostimulatie van de elektrode, toch overgegaan tot een RFTC-behandeling omdat de mogelijke winst van een ingreep voor de patiënt zwaarder woog dan de mogelijke complicatie. Bij twee van deze elf patiënten heeft dit geresulteerd in blijvende visuele klachten (tabel 4). Aangezien er aangenomen wordt dat in de $\mathrm{PVH}$ geen actieve neurologische functies terug te vinden zijn, nemen wij aan dat deze uitval het gevolg is van beschadiging (collateral damage) van aangrenzende witte stof. Daarnaast traden er enkele dagen na de coagulatie bij twee patiënten passagère klachten van meningeale prikkeling en milde temperatuursverhoging op. Er werden geen aanwijzingen voor infectie of subarachnoïdale bloeding gevonden. De klachten verdwenen spontaan na vijf tot acht dagen.

\section{Beschouwing}

De ervaringen met SEEG-RFTC in ACE Kempenhaeghe/ MUMC+ betreffen voornamelijk patiënten met PVH. Opvallend is dat er in deze groep geen relatie bestaat tussen de plaats of het aantal noduli en het succes van de behandeling. Bij SEEG bestaan er beperkingen in het aantal en de trajecten van de diepte-elektroden die geplaatst kunnen worden. Mede hierdoor lukt het meestal niet om al het heterotopisch weefsel te coaguleren. Indien er na RFTC nog aanvallen optreden terwijl er nog heterotopisch weefsel zichtbaar is op de post-RFTC MRI dan gelden dezelfde overwegingen als voor de eerste coagulatie,

\begin{tabular}{|c|c|c|c|c|c|}
\hline & & \multicolumn{4}{|c|}{ Effect_RFTC } \\
\hline \multicolumn{2}{|l|}{ Laatste_RFTC } & Aanvalsvrij & Verbetering & Geen verbetering & Totaal \\
\hline \multirow[t]{6}{*}{ ja ja Plaats_MRI_afw } & $\begin{array}{l}\text { rechts_periventriculair__ } \\
\text { temporo-occipitaal }\end{array}$ & $\mathbf{I}$ & 2 & $\mathbf{I}$ & 4 \\
\hline & $\begin{array}{l}\text { rechts_periventriculair_ } \\
\text { frontoparietaal }\end{array}$ & $\mathbf{I}$ & o & 0 & $\mathbf{I}$ \\
\hline & $\begin{array}{l}\text { links_periventriculair__ } \\
\text { temporo-occipitaal }\end{array}$ & 0 & $\mathbf{I}$ & $\mathbf{I}$ & 2 \\
\hline & $\begin{array}{l}\text { links_periventriculair__ } \\
\text { frontoparietaal }\end{array}$ & $\mathbf{I}$ & 0 & 0 & $\mathbf{I}$ \\
\hline & $\begin{array}{l}\text { rechts_en_links_periventri- } \\
\text { culair_temporo-occipitaal }\end{array}$ & 5 & 2 & 0 & 7 \\
\hline & $\begin{array}{l}\text { rechts_en_links_periventri- } \\
\text { culair_temporo-occipitaal _ } \\
\text { en_frontoparietaal }\end{array}$ & 0 & $\mathbf{I}$ & 0 & $\mathbf{I}$ \\
\hline Totaal & & 8 & 6 & 2 & I6 \\
\hline \multirow[t]{2}{*}{ Plaats_MRI_afw } & $\begin{array}{l}\text { rechts_periventriculair_ } \\
\text { temporo-occipitaal }\end{array}$ & & 3 & $\mathbf{I}$ & 4 \\
\hline & $\begin{array}{l}\text { links_periventriculair__ } \\
\text { temporo-occipitaal }\end{array}$ & & 0 & 2 & 2 \\
\hline \multicolumn{2}{|l|}{ Totaal } & & 3 & 3 & 6 \\
\hline
\end{tabular}

Tabel 3 lokalisatie MRI afwijkingen versus het effect van de RFTC-behandeling. 
Wetenschappelijk onderzoek

\begin{tabular}{|c|c|c|c|c|c|}
\hline Na RFTC & Geen & Visueel bovenkwadrant & Visueel anders & $\begin{array}{l}\text { Pariëtaal } \\
\text { (duizeligheid) }\end{array}$ & $\begin{array}{l}\text { Talig } \\
\text { (lezen) }\end{array}$ \\
\hline Geen & II & 3 & 3 & 2 & $\mathbf{I}$ \\
\hline Visueel & 0 & 0 & 2 & 0 & 0 \\
\hline Anders ${ }^{\star}$ & 0 & 0 & 0 & 0 & 0 \\
\hline
\end{tabular}

Tabel 4 Relatie tussen klinische verschijnselen tijdens elektrostimulatie van contactpunten die later zijn gecoaguleerd en klinische verschijnselen na RFTC ( bij PVH )

zodat er nog een tweede of zelfs derde implantatie met RFTC kan volgen. Ook daar gelden dezelfde restricties voor als bij de eerste poging. Toch wordt er vaak aanvalsvrijheid bereikt. De reden hiervoor kan zijn dat PVH niet obligatoir intrinsiek epileptogeen is. Dit wordt ondersteund door de bevinding dat ook tijdens de registratie van het SEEG PVH-regio's gezien worden die betrokken zijn bij (het begin van) de aanvallen en PVH-regio's die dat niet zijn. Een andere hypothese is dat er sprake is van een epileptogeen netwerk waarin de PVH kritische knooppunten (hubs) vormt. Bij uitschakeling van de juiste hubs wordt het netwerk uitgeschakeld. Volledige coagulatie van PVHweefsel blijkt niet steeds noodzakelijk. Nader wetenschappelijk onderzoek naar pre-implantatie differentiatie tussen epileptogene en niet-epileptogene regio's is daarom wenselijk. Daarbij zou bijvoorbeeld gedacht kunnen worden aan verschillende signaturen bij (rs-) fMRI, MRS, PET, SPECT en/of andere spike transients of evoked potentials in het SEEG signaal.

Bij de twee patiënten met meningeale klachten na RFTC was sprake van meer dan 40 bipolair uitgevoerde coagulaties binnen één SEEG-onderzoek. Onze hypothese is dat deze self-limiting symptomen het gevolg zijn van een asep- tische ontstekingsreactie op eiwit-afbraakproducten na coagulatie.

\section{Conclusies}

RFTC blijkt in het algemeen een relatief veilige behandelmethode te zijn, waarbij vooraf middels elektrostimulatie de mogelijke risico's goed in kaart gebracht kunnen worden. De persisterende visuele klachten traden alleen op bij patiënten met PVH. Aangezien PVH geen intrinsieke functies lijkt te hebben, duiden we symptomen optredend na elektrostimulatie in de PVH's als het gevolg van spreiding via banen in de witte stof of van stimulatie hiervan. Aangezien er vooralsnog geen goede methode bestaat om hier onderscheid tussen te maken, wordt het risico van een neurologisch deficit als gevolg van de behandeling altijd uitgebreid met de patiënten besproken.

$\mathrm{Al}$ met al levert RFTC een extra minimaal invasieve, in opzet curatieve, behandelmethode voor medicatie-resistente focale epilepsie met een prognostische potentie. Er bestaat een reële kans dat na RFTC verdere open epilepsiechirurgie niet meer geïndiceerd is. De bijkomende risico's op complicaties naast de al aanwezige risico's van een diepteelektroden implantatie zijn beperkt maar niet afwezig.

\section{Kijk voor meer informatie op www.epilepsieliga.nl.}

